Shareholder of: Pfizer Inc, Employee of: Pfizer Inc, Tatjana Lukic Shareholder of: Pfizer Inc, Employee of: Pfizer Inc, Shixue Liu Shareholder of: Pfizer Inc, Employee of: Pfizer Inc, Lori Stockert Shareholder of: Pfizer Inc, Employee of: Pfizer Inc, Noriko likuni Shareholder of: Pfizer Inc, Employee of: Pfizer Inc, Edward Keystone Grant/research support from: AbbVie, Amgen, Lilly Pharmaceuticals, Pfizer Inc, PuraPharm, Sanofi-Aventis, Consultant for: AbbVie, Amgen, AstraZeneca, Biotest, Bristol-Myers Squibb, Celltrion, Crescendo Bioscence, F. Hoffman-La Roche, Genentech, Gilead, Janssen, Lilly Pharmaceuticals, Merck, Pfizer Inc, Sandoz, Sanofi-Genzyme, Samsung Bioepis, UCB, Speakers bureau: AbbVie, Amgen, Bristol-Myers Squibb Canada, F. Hoffman-La Roche, Janssen, Merck, Pfizer Inc, Sanofi-Genzyme, UCB DOI: 10.1136/annrheumdis-2019-eular.8657

\section{LB0005 MULTICENTRE, RANDOMISED, OPEN-LABEL, ASSESSOR-BLINDED, PARALLEL-GROUP HEAD-TO- HEAD COMPARISON OF THE EFFICACY AND SAFETY OF IXEKIZUMAB VERSUS ADALIMUMAB IN PATIENTS WITH PSORIATIC ARTHRITIS NAIVE TO BIOLOGIC DISEASE-MODIFYING ANTI-RHEUMATIC DRUGS: 24- WEEK RESULTS}

Philip J. Mease ${ }^{1}$, Josef S. Smolen ${ }^{2}$, Frank Behrens ${ }^{3}$, Peter Nash ${ }^{4}$, Soyi Liu Leage ${ }^{5}$, LI Lingnan ${ }^{5}$, Hasan Tahir ${ }^{6}$, Melinda Gooderham ${ }^{7}$, Eswar Krishnan ${ }^{5}$, Paul Emery ${ }^{8}$, Sreekumar Pillai ${ }^{5}$, Philip Helliwell ${ }^{8}{ }^{1}$ Swedish Medical Center \& University of Washington, Seattle, United States of America; ${ }^{2}$ Medical University of Vienna, Vienna, Austria; ${ }^{3}$ Goethe University, Frankfurt, Germany; ${ }^{4}$ University of Queensland, Brisbane, Australia; ${ }^{5}$ Eli Lilly, Indianapolis, United States of America; ${ }^{6}$ Barts Health, London, United Kingdom; ${ }^{7}$ Skin Centre for Dermatology, Peterborough, Canada; ${ }^{8}$ NIHR BRC LTHT \& LIRRM, University of Leeds, United Kingdom

Background: There have been few head-to-head clinical trials comparing different biologic disease-modifying anti-rheumatic drugs (bDMARDs) in patients (pts) with psoriatic arthritis (PsA).

Objectives: To report 24-week (wk) results of a study directly comparing efficacy and safety of ixekizumab (IXE), an IL-17A inhibitor, and adalimumab (ADA), a TNF inhibitor, in bDMARD-naive pts with PsA.

Methods: The study (NCT03151551; SPIRIT-H2H) included pts with active PsA $(\geq 3 \mathrm{TJC}+\geq 3 \mathrm{SJC}$ ) and plaque psoriasis (BSA $\geq 3 \%$ ) who were bDMARD naive and inadequate responders to CsDMARD therapy. Patients were randomised (1:1) to IXE or ADA for 52 wks (on-label dosing based on presence/absence of moderate to severe psoriasis). The primary objective was superiority of IXE vs ADA measured by the proportion of pts achieving both ACR50 and PASI100 responses at wk 24. Key secondary objectives versus $A D A$ at wk 24 were (1) non-inferiority of IXE for ACR50 (noninferiority margin -12\%) and (2) superiority of IXE for PASI100. Additional PsA, skin, composite treat-to-target (T2T: MDA, DAPSA 4), PASDAS remission and patient-reported outcomes, and safety were assessed. Nine pts had $P A S I=0$ and $B S A \geq 3 \%$ (a medical inconsistency) at baseline; these pts were considered PASI100 responders if $P A S I=0$ and $B S A=0$ at wk 24. Categorical variables were evaluated using logistic regression analyses with NRI in the ITT population. Continuous variables were analysed using mixed models for repeated measure analysis.

Results: 566 pts were randomised (283 to IXE and 283 to ADA). Baseline demographics and disease characteristics were generally well balanced between groups (Table 1). All primary and key secondary efficacy endpoints at wk 24 were met (Figure). The proportion of pts achieving both ACR50 and PASI100 was significantly greater for IXE than ADA ( $36 \%$ vs $28 \%$; $p<0.05)$. IXE was non-inferior to ADA for ACR50 response and superior for PASI100 response (Figure). While improvements from baseline were achieved with both treatments, significantly better results were seen with IXE vs ADA for skin and composite T2T outcomes, enthesitis resolution (Figure 1), and skin-related quality of life (Table 2). No unexpected safety signals were observed.

Table 1. Patient baseline demographics/characteristics
\begin{tabular}{|l|c|c|}
\hline & $\begin{array}{c}\text { IXE } \\
(\mathbf{N}=\mathbf{2 8 3})\end{array}$ & $\begin{array}{c}\text { ADA } \\
(\mathbf{N}=\mathbf{2 8 3})\end{array}$ \\
\hline Age, years & $47.5(12.0)$ & $48.3(12.3)$ \\
\hline Male, $n(\%)$ & $162(57)$ & $150(53)$ \\
\hline PSA duration since diagnosis, years & $6.6(7.4)$ & $5.9(6.4)$ \\
\hline Concomitant csDMARD use, $n(\%)$ & $193(68)$ & $199(70)$ \\
\hline TJC & $19.1(12.7)$ & $21.3(15.4)$ \\
\hline SJC & $10.1(7.5)$ & $10.7(8.1)$ \\
\hline PASI & $7.9(8.7)$ & $7.7(7.3)$ \\
\hline
\end{tabular}

Data are mean (SD), unless stated otherwise
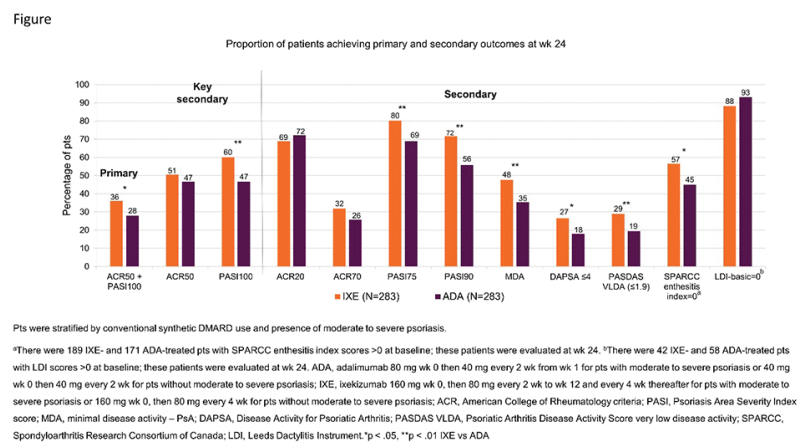

Table 2. Patient reported outcomes

\begin{tabular}{|l|c|c|c|c|}
\hline & \multicolumn{2}{|c|}{ IXE (N=283) } & \multicolumn{2}{c|}{ ADA (N=283) } \\
\hline & Baseline & $\begin{array}{c}\text { LS mean } \\
\text { change at wk } \\
\text { 24 }\end{array}$ & Baseline & $\begin{array}{c}\text { LS mean } \\
\text { change at } \\
\text { wk 24 }\end{array}$ \\
\hline HAQ-DI & 1.20 & -.63 & 1.27 & -.56 \\
\hline SF-36 PCS & 36.80 & 9.96 & 36.12 & 8.82 \\
\hline SF-36 MCS & 45.40 & 4.47 & 44.85 & 3.93 \\
\hline $\begin{array}{l}\text { Dermatology Life Quality } \\
\text { Index }\end{array}$ & 9.77 & $-7.81^{*}$ & 9.82 & -6.48 \\
\hline $\begin{array}{l}\text { Fatigue Severity Numeric } \\
\text { Rating Scale }\end{array}$ & 5.87 & -2.66 & 6.46 & -2.53 \\
\hline LS, least square; ${ }^{*}$ p<.001 vs ADA & \multicolumn{5}{l}{} \\
\hline
\end{tabular}

Conclusion: In bDMARD naive pts with active PsA and skin disease, IXE showed superior efficacy to ADA based on simultaneous achievement of ACR50 and PASI100 responses at wk 24. Greater improvements with IXE vs ADA were also attained in individual PsA domains and composite T2T outcomes.

Disclosure of Interests: Philip J Mease Grant/research support from: AbbVie, Amgen, Bristol-Myers Squibb, Celgene, Janssen, Leo, Eli Lilly, Merck, Novartis, Pfizer, Sun Pharmaceutical Industries, Inc., and UCB., Consultant for: AbbVie, Amgen, Bristol-Myers Squibb, Celgene, Galapagos, Gilead, Janssen, Leo, Eli Lilly, Merck, Novartis, Pfizer, Sun Pharmaceutical Industries, Inc., and UCB., Speakers bureau: AbbVie, Amgen, Bristol-Myers Squibb, Celgene, Genentech, Janssen, Leo, Merck, Novartis, Pfizer and UCB.., Josef S. Smolen Grant/research support from: AbbVie, Eli Lilly, Janssen, MSD, Pfizer Inc, Roche, Consultant for: AbbVie, Amgen, AstraZeneca, Astro, Celgene, Celtrion, Eli Lilly, GlaxoSmithKline, ILTOO, Janssen, Medimmune, MSD, Novartis-Sandoz, Pfizer Inc, Roche, Samsung, Sanofi, UCB, Speakers bureau: AbbVie, Amgen, AstraZeneca, Astro, Celgene, Celtrion, Eli Lilly, GlaxoSmithKline, ILTOO, Janssen, Medimmune, MSD, Novartis-Sandoz, Pfizer Inc, Roche, Samsung, Sanofi, UCB, Frank Behrens Grant/research support from: AbbVie, Pfizer, Roche, Chugai, Prophylix, Bioline, Novartis, Consultant for: AbbVie, Pfizer, Roche, Chugai, UCB, Bristol-Myers Squibb, Celgene, MSD, Novartis, Biotest, Janssen, Genzyme, Eli Lilly, Speakers bureau: Ad board: AbbVie, Pfizer, Roche, Chugai, UCB, Bristol-Myers Squibb, Celgene, Novartis, Biotest, Janssen, Genzyme, Eli Lilly, Peter Nash Grant/ research support from: AbbVie, Bristol-Myers Squibb, Eli Lilly, Janssen, Novartis, Pfizer Inc, Roche, Sanofi, UCB, MSD, Celgene, Gilead, Consultant for: AbbVie, Bristol-Myers Squibb, Eli Lilly, Janssen, Novartis, Pfizer Inc, Roche, Sanofi, UCB, MSD, Celgene, Gilead, Speakers bureau: AbbVie, Bristol-Myers Squibb, Eli Lilly, Janssen, Novartis, Pfizer Inc, Roche, Sanofi, UCB, MSD, Celgene, Gilead, Soyi Liu Leage Shareholder of: Eli Lilly and Company, Employee of: Eli Lilly and Company, Li Lingnan Shareholder of: Eli Lilly and Company, Employee of: Eli Lilly and Company, Hasan Tahir Grant/research support from: Novartis, Eli-Lilly, Speakers bureau: AbbVie, Janssen, Eli Lilly, and Novartis, Melinda Gooderham Grant/ research support from: Abbvie Inc., Actelion Pharmaceuticals, Akros Pharma Inc., AMGEN Inc., Arcutis Pharmaceuticals Inc., Boehringer Ingelheim International GmbH, Bristol-Myers Squibb, Celgene Corporation, Dermira Inc., Eli Lilly and Company, Galderma SA, Glenmark, Janssen Inc., LEO Pharma, Medlmmune, Merck and Co., Novartis Pharmaceuticals, Pfizer Inc., Regeneron Pharmaceuticals Inc., Roche Laboratories, Sanofi Genzyme, UCB, Valeant Pharmaceuticals Inc., Consultant for: Akros Pharma Inc., AMGEN Inc., Boehringer Ingelheim International $\mathrm{GmbH}$, Celgene Corporation, Eli Lilly and Company, Janssen Inc., Novartis Pharmaceuticals, Sanofi Genzyme, Valeant Pharmaceuticals Inc., Speakers bureau: Abbvie Inc., Actelion Pharmaceuticals, AMGEN Inc., Boehringer Ingelheim International $\mathrm{GmbH}$, Celgene Corporation, Eli Lilly and Company, Galderma SA, Glenmark, Janssen Inc., LEO Pharma, Novartis Pharmaceuticals, Pfizer Inc., Regeneron Pharmaceuticals Inc., Sanofi Genzyme, Valeant Pharmaceuticals Inc., Eswar Krishnan Shareholder of: Eli Lilly and 
Company, Employee of: Eli Lilly and Company, Paul Emery Grant/research support from: Pfizer, MSD, AbbVie, Bristol-Myers Squibb, Roche, Consultant for: Pfizer, MSD, AbbVie, Bristol-Myers Squibb, UCB, Roche, Novartis, Gilead,Samsung, Sandoz and Lilly, Sreekumar Pillai Shareholder of: Eli Lilly and Company, Employee of: Eli Lilly and Company, Philip Helliwell Grant/research support from: Paid to charity: from AbbVie, Janssen and Novartis, Consultant for: Paid to charity: from AbbVie, Amgen, Pfizer, and UCB and Celgene. Paid to self: from Celgene and Galapagos

DOI: 10.1136/annrheumdis-2019-eular.8709

\section{LB0006 PROVIDES SUSTAINED INHIBITION OF RADIOGRAPHIC PROGRESSION IN PSORIATIC ARTHRITIS OVER 2 YEARS: RESULTS FROM THE PHASE 3 FUTURE-5 TRIAL}

Philip J. Mease ${ }^{1}$, Robert B.M. Landewé ${ }^{2}$, Proton Rahman ${ }^{3}$, Hasan Tahir ${ }^{4}$, Atul Singhal ${ }^{5}$, Elke Boettcher ${ }^{6}$, Sandra Navarra ${ }^{7}$, Aimee Readie $^{8}$, Shephard Mpofu ${ }^{9}$, Eumorphia Maria Delicha ${ }^{9}$, Luminita Pricop ${ }^{8}$, Désirée van der Heijde ${ }^{10}$. ${ }^{1}$ Swedish Medical Centre and University of Washington, Seattle, United States of America; ${ }^{2}$ University of Amsterdam and Atrium Medical Centre, Amsterdam, Netherlands; ${ }^{3}$ Memorial University, Newfoundland and Labrador, Canada; ${ }^{4}$ Whipps Cross Hospital, London, United Kingdom; ${ }^{5}$ Southwest Rheumatology, Dallas, United States of America; ${ }^{6}$ Rheumazentrum Favoriten, Vienna, Austria; ${ }^{7}$ University of Santo Tomas Hospital, Manila, Philippines; ${ }^{8}$ Novartis Pharmaceuticals Corp., East Hanover, United States of America; ${ }^{9}$ Novartis Pharma AG, Basel, Switzerland; ${ }^{10}$ Leiden University Medical Centre, Leiden, Netherlands

Background: Secukinumab (SEC) provided sustained clinical efficacy, and inhibition of radiographic progression over 52 Weeks (Wks) in patients (pts) with psoriatic arthritis (PsA) in the FUTURE 5 study $^{1}$.

Objectives: To report the effect of SEC on radiographic progression at Wk 104 (2 years) in PsA pts in the FUTURE 5 study.

Methods: Adults $(\mathrm{N}=996)$ with active PsA, stratified by prior anti-TNF therapy (naïve and inadequate response/intolerance [IR]) were randomised 2:2:2:3 to subcutaneous SEC 300mg with loading dose (LD; 300mg), 150mg LD (150mg), $150 \mathrm{mg}$ no LD, or placebo at baseline (BL), Wks 1, 2, 3, 4, and every 4 wks thereafter. Pts could have SEC dose escalated from 150 to $300 \mathrm{mg}$ starting from Wk 52 , based on physicians' judgement. Data are shown for pts originally randomised to SEC; $150 \mathrm{mg}$ groups include pts who had dose escalated to $300 \mathrm{mg}$. Concomitant MTX ( $\leq 25 \mathrm{mg} /$ week) was allowed. Radiographic progression (mean change in van der Heijde-modified total Sharp score [vdH-mTSS] and its components: erosion and joint space narrowing [JSN] scores, was based on hand/wrist/foot Xrays obtained at $\mathrm{BL}$ and $\mathrm{Wk} 104$, and assessed by two blinded readers (plus an adjudicator if required). Other efficacy endpoints included ACR20/50, PASI90 and resolution of dactylitis and enthesitis.

\begin{tabular}{|c|c|c|c|}
\hline \multicolumn{4}{|c|}{ Table. Summary of Efficacy Results } \\
\hline \multicolumn{4}{|c|}{ Mean change in vdH-mTSS scores from BL to Wk 104 (BL score) } \\
\hline & $\begin{array}{l}300 \mathrm{mg} \\
N=222 \\
n=191\end{array}$ & $\begin{array}{c}\text { 150mg group* } \\
\qquad \begin{array}{c}N=220 \\
n=181\end{array}\end{array}$ & $\begin{array}{c}\text { 150mg no LD } \\
\text { group* } \\
\mathrm{N}=222 \\
\mathrm{n}=169\end{array}$ \\
\hline vdH-mTSS & $0.37(12.07)$ & $0.52(11.47)$ & $0.41(13.99)$ \\
\hline Erosion & $0.27(7.15)$ & $0.27(6.67)$ & $0.38(8.07)$ \\
\hline JSN & $0.11(4.92)$ & $0.24(4.79)$ & $0.03(5.92)$ \\
\hline \multicolumn{4}{|c|}{ Clinical responses at Wk 104 (\% responders [n]) } \\
\hline & $\begin{array}{l}300 \mathrm{mg} \\
\mathrm{N}=222\end{array}$ & $\begin{array}{c}150 \text { mg group* } \\
N=220\end{array}$ & $\begin{array}{c}150 \text { mg no LD } \\
\text { group* } \\
\mathrm{N}=222\end{array}$ \\
\hline ACR20 & $77.0(187)$ & $79.4(175)$ & $78.0(168)$ \\
\hline ACR50 & $51.9(187)$ & $52.6(175)$ & $57.7(168)$ \\
\hline PASI90 $^{1}$ & $70.1(97)$ & $59.2(103)$ & $62.6(91)$ \\
\hline Resolution of enthesitis ${ }^{2}$ & $78.0(118)$ & $80.3(117)$ & $69.5(95)$ \\
\hline Resolution of dactylitis ${ }^{3}$ & $82.8(64)$ & $85.5(62)$ & $89.3(75)$ \\
\hline \multicolumn{4}{|c|}{$\begin{array}{l}\text { Observed data } \\
{ }^{*} 150 \mathrm{mg} \text { and } 150 \mathrm{mg} \text { no load arms include } 86 \text { and } 92 \text { pts, respectively, who were dose escalated at Wk } 52 \text { or later. } \\
\text { N, number of pts randomised; } n \text {, number of pts with data at BL and Wk } 104 . \\
\text { Data from pts with: }{ }^{1} \text { BL psoriasis } 23 \% \text { body surface area, }{ }^{2} \text { enthesitis at BL, }{ }^{3} \text { dactylitis at BL }\end{array}$} \\
\hline
\end{tabular}

Results: Overall, $84.7 \%$ (300mg), 82.3\% (150mg) and 75.2\% (150mg no LD) pts completed 2 years of treatment. A total of $86(39 \%)$ and $92(41 \%)$ pts had their dose escalated to $300 \mathrm{mg}$ in the $150 \mathrm{mg}$ and $150 \mathrm{mg}$ no LD groups, respectively. Inhibition of radiographic progression was sustained with SEC through 2 years (Table 1). Proportions of pts with no radiographic progression (change from BL in mTSS $\leq 0.5)$ with SEC were 89.5\% (300 mg), 82.3\% (150 mg), and 81.1\% (150 $\mathrm{mg}$ no LD) at 2 years; corresponding proportion of pts for change from BL in mTSS $\leq 0.0$ were: $81.2 \%, 69.1 \%$ and $73.4 \%$, respectively. Clinical responses were also sustained through 2 years (Table 1).

Conclusion: Subcutaneous secukinumab provided sustained inhibition of radiographic progression and sustained clinical responses through 2 years of treatment in pts with active PsA

\section{REFERENCE}

[1] Mease PJ et al. Arthritis Rheumatol 2018;70(suppl 10).

Disclosure of Interests: Philip J Mease Grant/research support from: AbbVie, Amgen, Bristol-Myers Squibb, Celgene, Janssen, Leo, Eli Lilly, Merck, Novartis Pfizer, Sun Pharmaceutical Industries, Inc., and UCB., Consultant for: AbbVie, Amgen, Bristol-Myers Squibb, Celgene, Galapagos, Gilead, Janssen, Leo, El Lilly, Merck, Novartis, Pfizer, Sun Pharmaceutical Industries, Inc., and UCB. Speakers bureau: AbbVie, Amgen, Bristol-Myers Squibb, Celgene, Genentech, Janssen, Leo, Merck, Novartis, Pfizer and UCB.., Robert B.M. Landewé: None declared, Proton Rahman Grant/research support from: Investigator for Janssen Research \& Development, LLC and Novartis, Consultant for: AbbVie, Amgen, Bristol-Myers Squibb, Celgene, Janssen, Eli Lilly,Novartis, and UCB, Speakers bureau: AbbVie, Amgen, Bristol-Myers Squibb, Celgene, Janssen, Eli Lilly, and Novartis, Hasan Tahir Grant/research support from: Novartis, Eli-Lilly, Speakers bureau: AbbVie, Janssen, Eli Lilly, and Novartis, Atul Singhal Grant/research sup port from: AAbbVie, Gilead, Sanofi, Regeneron, Amgen, Roche, BMS, Janssen, Lilly, Novartis, Pfizer, UCB, Astra Zeneca, Medlmmune, FujiFilm, Nichi-lko, Mallinckrodt, Speakers bureau: AbbVie, Elke Boettcher Consultant for: Amgen, Roche, Eli Lilly, Pfizer, MSD, Novartis, Speakers bureau: Amgen, Roche, Eli Lilly, Pfizer, MSD, Novartis, Sandra Navarra Speakers bureau: Astellas, Johnson \& Johnson, Novartis, Pfizer, Aimee Readie Shareholder of: Novartis, Employee of: Novartis, Shephard Mpofu Shareholder of: Novartis, Employee of: Novartis Eumorphia Maria Delicha Consultant for: Novartis, Luminita Pricop Shareholder of: Novartis, Employee of: Novartis, Désirée van der Heijde Consultant for: AbbVie, Amgen, Astellas, AstraZeneca, Bristol-Myers Squibb, Boehringer Ingelheim, Celgene, Daiichi, Eli-Lilly, Galapagos, Gilead, GlaxoSmithKline, Janssen, Merck, Novartis, Pfizer, Regeneron, Roche, Sanofi, Takeda, Union Chimique Belge DOI: 10.1136/annrheumdis-2019-eular.8808

\section{LB0007 \\ SUBCUTANEOUS TANEZUMAB FOR OSTEOARTHRITIS PAIN: A 24-WEEK PHASE 3 STUDY WITH A 24-WEEK FOLLOW UP}

Francis Berenbaum $^{1}$, Francisco J. Blanco ${ }^{2}$, Ali Guermazi ${ }^{3}$, Eric Vignon ${ }^{4}$, Kenji Miki $^{5}$, Takaharu Yamabe ${ }^{6}$, Lars Viktrup ${ }^{7}$, Rod Junor $^{8}$, William Carey ${ }^{8}$, Mark Brown ${ }^{6}$, Ken Verburg ${ }^{6}$, Christine West ${ }^{6} .{ }^{1}$ Sorbonne Universite, INSERM, APHP Hospital Saint Antoine, Paris, France; ${ }^{2}$ INIBIC-Complexo Hospitalario Universitario de A Coruña, A Coruña, Spain; ${ }^{3}$ Boston University School of Medicine, Boston, United States of America; ${ }^{4}$ Université Claude Bernard, Lyon, France; ${ }^{5}$ Osaka Yukioka College of Health Science, Hayaishi Hospital, Osaka, Japan; ${ }^{6}$ Pfizer Inc, Groton, United States of America; ${ }^{7}$ Eli Lilly \& Company, Indianapolis, United States of America; ${ }^{8}$ Pfizer Ltd, Tadworth, United Kingdom

Background: Tanezumab, a monoclonal antibody against nerve growth factor, is in development for treatment of osteoarthritis $(\mathrm{OA})$ pain

Objectives: To assess efficacy and safety of tanezumab in patients with moderate to severe OA pain who have not responded to or cannot tolerate standard of care analgesics.

Methods: A randomized, double-blind, placebo-controlled study (24 week treatment; 24 week follow-up) was conducted in patients in Europe and Japan with moderate to severe OA pain of the knee or hip and history of insufficient pain relief or intolerance to acetaminophen, oral nonsteroidal anti-inflammatory drug, and either tramadol or opioids (or unwilling to take opioids). Patients received subcutaneous tanezumab (2.5 or $5 \mathrm{mg}$ ) or placebo at baseline, week 8 , and week 16 . Coprimary endpoints were change from baseline in Western Ontario and McMaster Universities Osteoarthritis Index (WOMAC) Pain, WOMAC Physical Function, and Patient Global Assessment of OA (PGA-OA) scores at week 24. Safety, including independent adjudication of joint safety events, was assessed.

Results: Tanezumab 5 mg met all co-primary endpoints (Fig. 1). Tanezumab 2.5 mg met WOMAC Pain and Physical Function endpoints but not the PGA-OA endpoint; thus, this dose did not meet pre-specified efficacy criteria. The occurrence 